\title{
Por Que Vale a Pena Usar Mapas Conceituais no Ensino Superior?
}

\author{
Paulo R. M. Correia*1, Joana G. Aguiar², Anderson D. Viana² e \\ Gisele C. P. Cabral² \\ ${ }^{1}$ Escola de Artes, Ciências e Humanidades da Universidade de São Paulo \\ Programa de Pós-Graduação Interunidades em Ensino de Ciências da Universidade de São Paulo
}

* Autor para correspondência: prmc@usp.br

\section{RESUMO}

Aprender profundamente, aprender a aprender (metalearning) e aprender por toda a vida (lifelong learning) são alguns dos novos desafios que a sociedade do conhecimento apresenta ao ensino superior. $\mathrm{O}$ aumento do interesse por métodos e estratégias inovadoras, que alterem a dinâmica da sala de aula, tem produzido boas respostas. Esse artigo apresenta a técnica de mapeamento conceitual para favorecer a aprendizagem profunda, que aproxima o aluno do conhecimento especializado do professor. A possibilidade de oferecer feedbacks precisos e constantes ao longo do processo de ensino-aprendizagem justifica o uso dos mapas conceituais no ensino superior. O domínio da técnica de mapeamento conceitual e o planejamento cuidadoso da demanda a ser apresentada em sala de aula são aspectos fundamentais para assegurar os resultados esperados.

Palavras-chave: Mapas Conceituais; Ensino Superior; Aprendizagem Profunda; Avaliação da Aprendizagem; Aprendizagem por Toda a Vida; Meta-aprendizagem.

\begin{abstract}
Deep learning, metalearning and lifelong learning are some of the new challenges presented by the knowledge society to higher education. The interest in innovative methods and strategies that change the dynamics of the classroom has increased and produced good responses. This paper presents concept mapping as a way to encourage deep learning, which approximates students and the teacher's expert knowledge. The ability to provide accurate and constant feedback throughout the teaching-learning process justifies the use of concept maps in higher education. The mastery of the concept mapping technique and the careful planning of the demand to be presented in the classroom are critical to ensure the expected results.
\end{abstract}

Keywords: Concept Maps; Higher Education; Deep Learning; Learning Evaluation; Lifelong Learning; Metalearning.

\section{Introdução}

O sistema de ensino superior está se reinventando. Atualmente, ele opera numa sociedade forjada a partir da explosão do conhecimento e do desenvolvimento das tecnologias da informação e comunicação. A sociedade do conhecimento emerge como resultado das transformações iniciadas na metade final do século XX, que tornaram obsoletos os paradigmas da sociedade industrial (FRIEDMAN, 2007). Espaço e tempo ganharam novos significados no mundo contemporâneo como decorrência da globalização. A crescente importância da ciência, da tecnologia e da inovação demanda novas formas de criar e disseminar o conhecimento.
Aprender a aprender (metalearning) e aprender por toda a vida (lifelong learning) são essenciais para que os egressos exerçam de forma competente e responsável suas funções na sociedade. A universidade que funcionou adequadamente na sociedade industrial não antende a essas demandas, e é preciso buscar novos caminhos (UNESCO, 2005). As instituições de ensino superior estão desafiadas a propor soluções para formar cidadãos e profissionais que sejam capazes de não só de aplicar tecnicamente o conhecimento específico, mas também de criar soluções inovadoras que respondam a problemas presentes e futuros numa sociedade cada vez mais complexa. 
O processo de ensino-aprendizagem é um dos alvos dessa transformação. São vários os docentes e alunos que ficam insatisfeitos com os resultados obtidos em sala de aula, apesar dos esforços dedicados às disciplinas de graduação. Estuda-se muito, mas se aprende menos do que o desejado. $\mathrm{O}$ entendimento dessa situação exige o reconhecimento e a valorização das pesquisas acadêmicas que formam um arcabouço teórico-conceitual a partir de contribuições de várias áreas do conhecimento, tais como a educação, a psicologia, a epistemologia e os campos de conhecimento específico dos cursos de graduação. Essa valiosa fonte de informação deve nortear as discussões sobre como ensinar e aprender no ensino superior. O objetivo deste artigo é apresentar a técnica de mapeamento conceitual e aplicações para responder por que vale a pena usar mapas conceituais no ensino superior.

\section{Mas o que São os Mapas Conceituais?}

Os mapas conceituais são organizadores gráficos que representam o conhecimento, a partir de proposições que contém três elementos: conceito inicial, termo de ligação e conceito final. Apresentados por Joseph Novak no início da década de 1970, os mapas conceituais têm sido largamente utilizados para organizar e compartilhar conhecimentos no âmbito educacional, em grupos de pesquisa e nas corporações (e.g. MOON et al., 2011; CORREIA, 2012; IFENTHALER \& HANEWALD, 2014; NOVAK, 2010; TORRES \& MARRIOTT, 2010).

O termo de ligação explicita, de forma clara e precisa, a relação entre os conceitos, conferindo clareza semântica à proposição. Um mapa conceitual pode ser entendido como um conjunto interconectado de proposições que contém mensagens inteligíveis com o objetivo de expressar relações conceituais. A Figura 1 mostra duas estruturas para destacar o papel central do termo de ligação na representação do conhecimento por meio de relações conceituais. A primeira estrutura (Figura 1a) não revela as relações entre os conceitos, limitando-se a associá-los (os pontos de interrogação nas setas simbolizam a ausência das relações conceituais). Por exemplo, os conceitos "clareza" e "comunicação" estão associados entre si, mas não há nenhuma indicação sobre como se dá a relação entre eles. A Figura 1b, por sua vez, apresenta termos de ligação em todas as setas que ligam os conceitos, evidenciando com precisão as relações conceituais estabelecidas. Nesse caso, é possível compreender que a "clareza" favorece a "comunicação (Figura 1b, proposição 11).

Inúmeras relações conceituais podem ser estabelecidas entre dois conceitos. $\mathrm{O}$ uso do termo de ligação, contendo um verbo, permite distinguir o conteúdo semântico das proposições e julgar a correção conceitual de cada uma delas. Pense, por um instante, como você relaciona os conceitos "USP" e "cursos de graduação". Agora, veja a Tabela 1 e oito formas de relacionar esses conceitos (as duas primeiras não são consideradas proposições). Note como pequenas alterações no termo de ligação produzem grandes transformações no significado da relação conceitual. É fácil identificar proposições inapropriadas (conceitualmente erradas) e proposições apropriadas (conceitualmente corretas) quando o conteúdo semântico é expresso com clareza. Por exemplo, podemos admitir que "USP - ofereceu $\rightarrow$ cursos de graduação" é uma proposição inapropriada porque ela ainda oferece cursos de graduação (o tempo verbal não está bem ajustado e compromete a fidelidade do conteúdo semântico). A proposição "USP - oferece $\rightarrow$ cursos de graduação" revela-se apropriada por conta da alteração do tempo verbal (feita a partir da remoção do morfema "u", transformando ofereceu em oferece). A inclusão de um adjetivo no termo de ligação ("USP - oferece bons $\rightarrow$ cursos de graduação") mantém a correção conceitual, mas aumenta a precisão da mensagem comunicada. Em síntese, a clareza semântica se mostra fundamental para que seja possível avaliar a correção conceitual e a adequação das proposições de um mapa conceitual.

A utilização adequada dos mapas conceituais depende do entendimento dessa técnica de representação do conhecimento. $\mathrm{O}$ treinamento na elaboração de mapas conceituais deve ser uma preocupação de todo mapeador iniciante, seja ele docente ou aluno. 

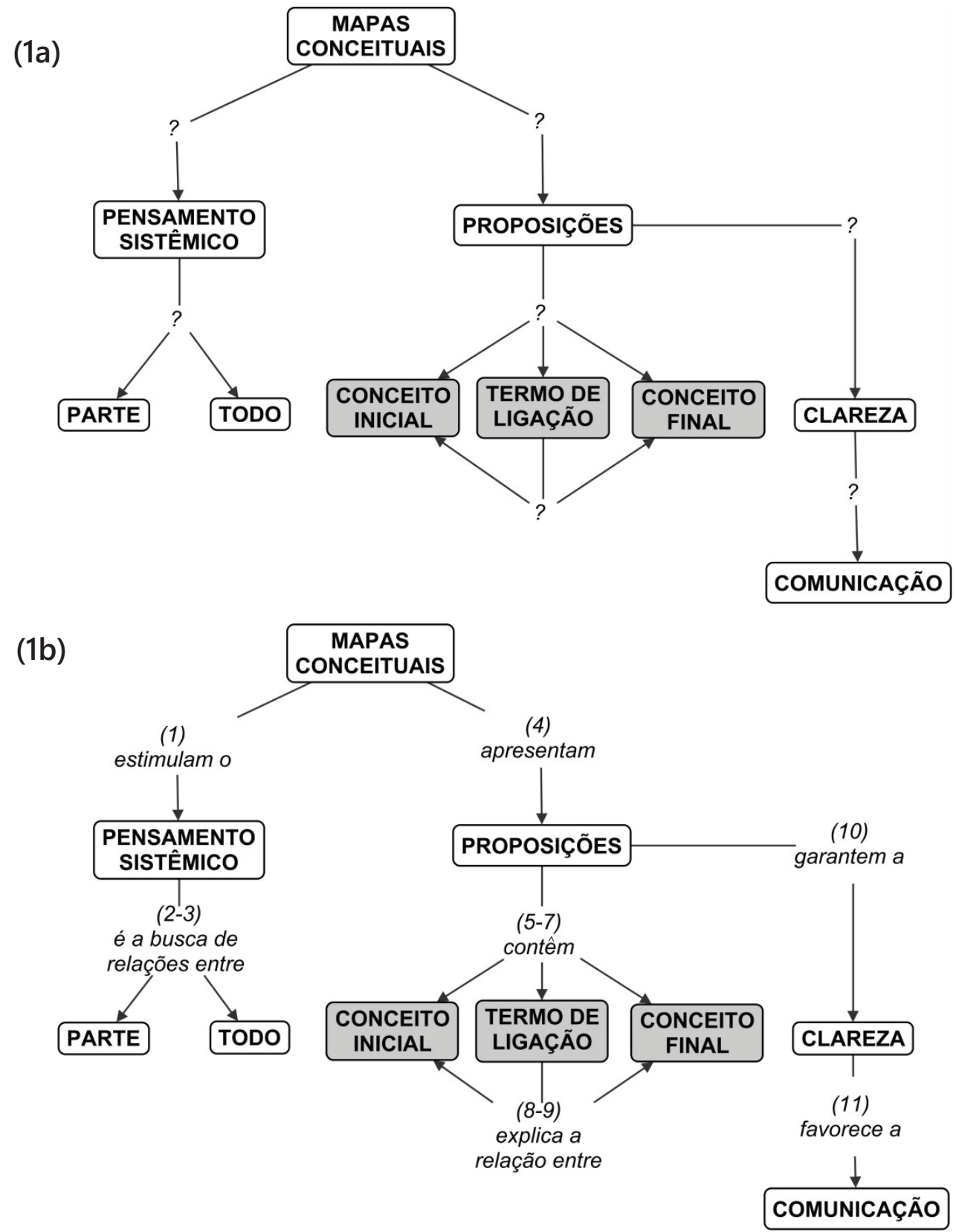

Figura 1 - Estruturas conceituais que respondem "Como os mapas conceituais ajudam na comunicação?": (a) não apresenta termos de ligação, limita o entendimento do conteúdo e revela somente a associação entre conceitos; (b) apresenta termos de ligação, que ampliam o conteúdo semântico e revelam com precisão as relações conceituais. Somente (b) pode ser classificada como mapa conceitual.

Há quatro parâmetros de referência que precisam ser observados por todo mapeador (AGUIAR \& CORREIA, 2013):

- As proposições devem ter alta clareza semântica e comunicar com precisão as relações conceituais representadas;

- A pergunta focal delimita o conteúdo a ser mapeado e é a forma mais eficiente para controlar o tamanho do mapa conceitual;

- A organização dos conceitos deve ser hierárquica, sendo que os conceitos mais gerais (abrangentes) ini- ciam o mapa e são progressivamente detalhados;

- As revisões contínuas do mapa conceitual devem ser utilizadas para modificar o conhecimento representado, de acordo com as mudanças de entendimento conceitual do mapeador.

O nosso grupo de pesquisa desenvolveu uma sequência de atividades visando ao aumento de proficiência na técnica de mapeamento conceitual. Os participantes dos workshops sobre mapas conceituais, promovidos pela USP e por outras instituições de ensino superior, utilizam essas ativi- 


\begin{tabular}{|c|c|c|c|}
\hline Proposição & Está clara? & Está correta? & Comentários \\
\hline $\begin{array}{c}\text { USP - ???? } \rightarrow \text { cursos } \\
\text { de graduação }\end{array}$ & Não & Não sei & $\begin{array}{l}\text { Ausência do termo de ligação. Os conceitos estão associa- } \\
\text { dos, mas nada pode ser dito sobre a relação conceitual. Essa } \\
\text { estrutura não é uma proposição. }\end{array}$ \\
\hline $\begin{array}{l}\text { USP }- \text { e } \rightarrow \text { cursos de } \\
\text { graduação }\end{array}$ & Não & Não sei & $\begin{array}{l}\text { Ausência de verbo no termo de ligação. A associação aditiva dos } \\
\text { conceitos gera um novo conceito único que remete aos "cursos } \\
\text { de graduação da USP". Não há relação dele com outro conceito. } \\
\text { Essa estrutura é uma proposição mal formulada por causa da } \\
\text { ausência de verbo no termo de ligação. }\end{array}$ \\
\hline $\begin{array}{c}\text { USP - oferece } \rightarrow \\
\text { cursos de graduação }\end{array}$ & Sim & Sim & $\begin{array}{l}\text { O termo de ligação contém verbo e o conteúdo semântico é } \\
\text { expresso de forma clara e precisa. É possível julgar a correção } \\
\text { conceitual da relação proposta. Nesse caso, a escolha do verbo } \\
\text { "oferecer" no presente do indicativo é adequada. }\end{array}$ \\
\hline $\begin{array}{l}\text { USP - ofereceu } \rightarrow \\
\text { cursos de graduação }\end{array}$ & Sim & Não & $\begin{array}{l}\text { O uso do verbo "oferecer" no pretérito perfeito não compro- } \\
\text { mete a clareza do conteúdo semântico, visto que é possível } \\
\text { julgar a correção conceitual. Todavia, nesse caso, o tempo } \\
\text { verbal torna inválida a proposição, uma vez que a USP ain- } \\
\text { da oferece cursos de graduação. }\end{array}$ \\
\hline $\begin{array}{l}\text { USP - oferecerá } \rightarrow \\
\text { cursos de graduação }\end{array}$ & Sim & Não & $\begin{array}{l}\text { O uso do verbo "oferecer" no futuro do presente não compro- } \\
\text { mete a clareza do conteúdo semântico, mas torna a proposição } \\
\text { inválida porque a USP já oferece cursos de graduação. }\end{array}$ \\
\hline $\begin{array}{l}\text { USP - não oferece } \rightarrow \\
\text { cursos de graduação }\end{array}$ & Sim & Não & $\begin{array}{l}\text { A inclusão de advérbios não compromete a clareza da } \\
\text { proposição, mas altera drasticamente o seu conteúdo } \\
\text { semântico. A inclusão do "não" invalida a proposição } \\
\text { porque a USP oferece cursos de graduação. }\end{array}$ \\
\hline $\begin{array}{l}\text { USP - oferece } \\
\text { muitos } \rightarrow \text { cursos de } \\
\text { graduação }\end{array}$ & Sim & Sim & $\begin{array}{l}\text { A inclusão de adjetivos pode conferir maior precisão ao conte- } \\
\text { údo semântico, ao qualificar o conceito final. A adição de "mui- } \\
\text { tos" torna a proposição adequada ainda mais precisa e exata. }\end{array}$ \\
\hline $\begin{array}{l}\text { USP - oferece } \\
\text { bons } \rightarrow \text { cursos de } \\
\text { graduação }\end{array}$ & Sim & Sim & $\begin{array}{l}\text { O adjetivo "bom" aumenta a precisão do conteúdo semân- } \\
\text { tico. A adequação da proposição pode ser avaliada e uma } \\
\text { discussão sobre a sua exatidão pode ser feita. Os cursos de } \\
\text { graduação da USP são bons, ótimos ou excelentes? }\end{array}$ \\
\hline
\end{tabular}

Tabela 1 - Comparação do conteúdo semântico de várias proposições envolvendo os conceitos USP (inicial) e cursos de graduação (final).

dades e o programa CmapTools ${ }^{1}$ para construir mapas conceituais (NOVAK \& GAÑAS, 2007). Os resultados obtidos até o momento são encorajadores e atestam que já existem bons mapeadores inovando suas práticas de sala de aula com os mapas conceituais.

A utilização contínua do mapeamento conceitual aumenta a nossa capacidade de organizar estruturas de conhecimento e expressá-las com clareza, a partir de proposições cuidadosamente selecionadas. Mapeadores excelentes combinam proficiência na técnica e alto domínio do conteúdo para criar mapas conceituais concisos, delimitados por uma pergunta focal e que se configuram como uma representação do conhecimento em alta fidelidade (CAÑAS, NOVAK \& REISKA, 2015). A Figura 2 expressa as diferenças entre os mapas conceituais bons e excelentes, sugerindo que o entendimento profundo da técnica de mapeamento conceitual depende da persistência. Em outras palavras, a utilização esporádica dos mapas conceituais dificilmente produzirá os resultados esperados na sala de aula.

\section{Mapeando o Processo de Ensino-Aprendizagem}

$\mathrm{O}$ processo de ensino-aprendizagem pode ser compreendido como a negociação de significados 


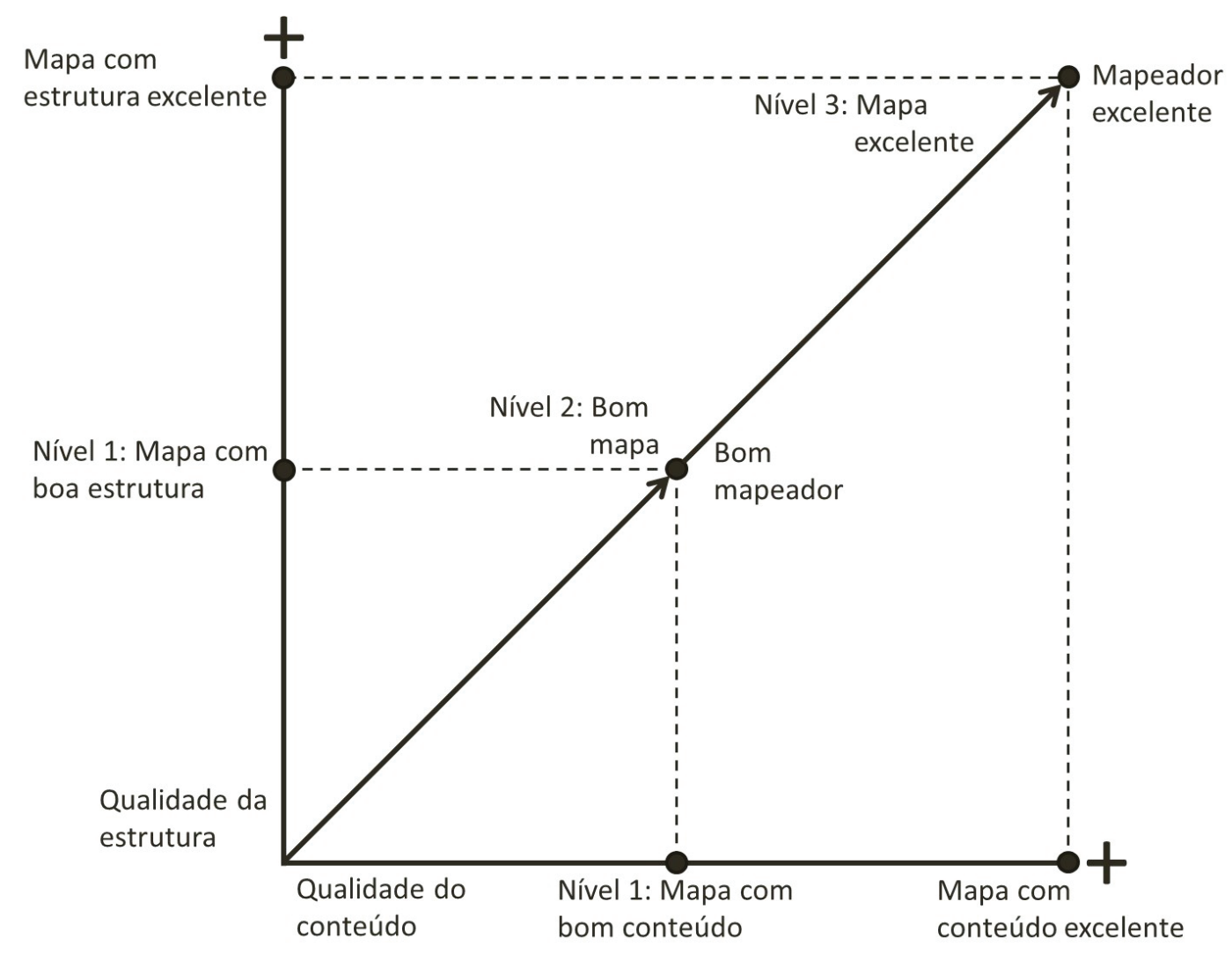

Figura 2 - Estrutura e conteúdo são critérios que definem a qualidade dos mapas conceituais. Boa estrutura e bom conteúdo resultam em mapas feitos por bons mapeadores com proficiência na técnica. Excelentes estrutura e conteúdo resultam em mapas feitos por excelentes mapeadores, proficientes na técnica e especialistas no assunto mapeado. Traduzido e adaptado de CAÑAS, NOVAK \& REISKA (2015), com permissão.

entre o professor (especialista) e os alunos (iniciantes no tema). Tais significados estão impregnados pelos conceitos e proposições existentes nas estruturas de conhecimento desses indivíduos. É plausível supor que, no início de uma disciplina, o professor possua uma estrutura de conhecimento mais detalhada e melhor organizada do que os seus alunos. Os mapas conceituais são úteis para caracterizar essas estruturas, bem como para monitorar as mudanças que elas sofrem durante o processo de ensino-aprendizagem (HAY, 2007; KINCHIN \& HAY, 2000; KINCHIN, LYGO-BAKER, HAY, 2008).

A Figura 3 apresenta mapas conceituais que tratam da USP usando os mesmos seis conceitos, mas que revelam diferentes níveis de entendimento sobre o tema. A estrutura radial (Figura 3a) é resultado dos poucos conhecimentos que o mapeador tem sobre o assunto, confirmando a existência de uma oportunidade para iniciar o aprendizado. Geralmente, os alunos possuem estruturas de conhecimento radiais no início de uma disciplina. A "USP" é o conceito de partida para todos os demais, que se referem a alguns aspectos específicos da universidade. A estrutura radial sugere que o mapeador não consegue identificar relações entre os demais conceitos do mapa. Por exemplo, as relações da "USP" com "alunos" (Figura 3a, proposição 2) e "cursos de graduação" (Figura 3a, proposição 4) estão declaradas, mas não há nenhum elo conceitual entre "alunos" e "cursos de graduação". Esse padrão revela que o mapeador tem pouco domínio conceitual sobre o tema, impedindo que ele expresse relações conceituais importantes para tratar da "USP". O processo de ensino-aprendizagem deve ser planejado a partir dos conhecimentos iniciais que os alunos possuem.

A estrutura linear (Figura 3b) revela um encadeamento sequencial dos conceitos. Nesse caso, o entendimento que o mapeador possui sobre o tema é suficiente para criar relações conceituais 

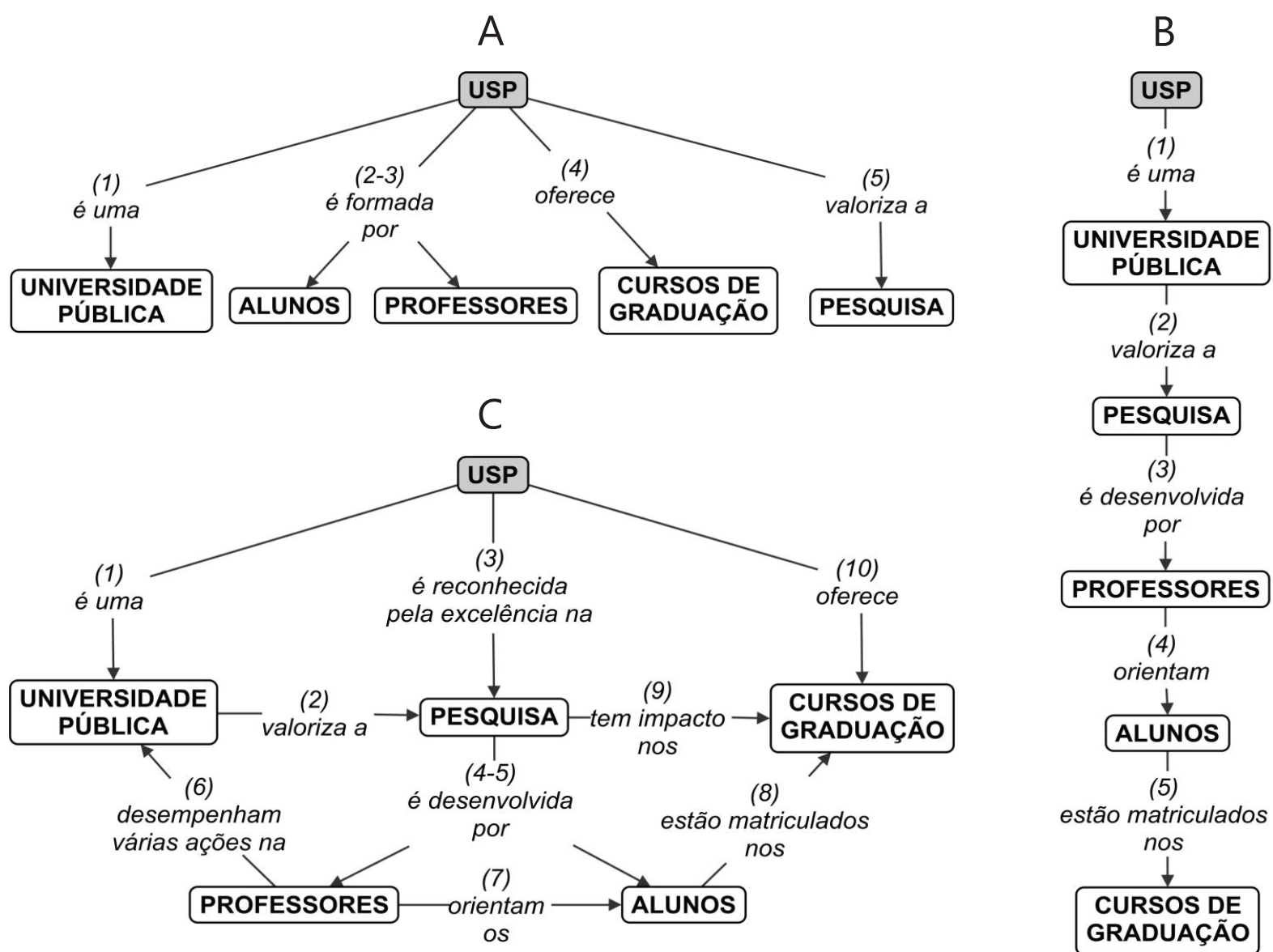

Figura 3 - Comparação de mapas conceituais sobre a USP contendo os mesmos conceitos ( $\mathrm{n}=6)$ : (a) estrutura radial, que apresenta proposições a partir de um único conceito e sugere pouco domínio sobre o tema; (b) estrutura linear, que apresenta encadeamento sequencial dos conceitos e sugere que algum domínio sobre o tema; (c) estrutura em rede, que apresenta conceitos inter-relacionados e sugere alto domínio sobre o tema. Adaptado de KINCHIN \& HAY (2000), com permissão.

sem abusar do uso exclusivo da "USP" como conceito inicial. Conceitos não relacionados na estrutura radial aparecem conectados na estrutura linear. Por exemplo, as relações da "pesquisa" com "professores" (Figura 3b, proposição 3) e dos "alunos" com os "cursos de graduação" (Figura 3b, proposição 5) são indicadores de um aumento do domínio sobre o tema. Obviamente, faz-se necessário avaliar se as proposições desse mapa conceitual são aceitáveis, considerando a natureza conceitual do conteúdo representado. Vale a pena destacar que o professor consegue visualizar com maior clareza a forma pela qual os alunos organizam suas estruturas de conhecimento, facilitando a identificação de conteúdos específicos que precisam ser retrabalhados. A regulação da aprendizagem pode ser feita com maior eficiência, pois o professor tem condições de individualizar seus comentários acerca do entendimento conceitual dos seus alunos.

A Figura 3c mostra uma estrutura em rede, na qual os conceitos rompem o encadeamento linear e passam a participar de múltiplas proposições. Note, por exemplo, que a "pesquisa" é o conceito mais acionado na rede proposicional (ele participa de cinco proposições diferentes). O conceito "alunos", antes relacionado somente com "cursos de graduação" (Figura 3b, proposição 5), aparece em proposições com "pesquisa" (Figura 3c, proposição 5), "professores" (Figura 3c, proposição 7) e "cursos de graduação" (Figura 3c, proposição 8). A grande inter-relação dos conceitos sugere alto domínio sobre o tema, ainda que inadequações conceituais possam ser identificadas e corrigidas. 
As estruturas em rede apresentam maior quantidade de proposições do que as demais e caracterizam o conhecimento especializado. Em outras palavras, o mapa conceitual do professor sobre sua própria disciplina tem a forma de uma rede.

A aprendizagem sobre um dado tema provoca alterações nas nossas estruturas de conhecimento, aumentando o nível de articulação entre os conceitos. O processo de ensino-aprendizagem deve promover alterações nas estruturas de conhecimento dos alunos, fazendo com que a organização radial (Figura 3a) evolua na direção de uma organização em rede (Figura 3c), a qual deve ser similar à estrutura de conhecimento do especialista. Alunos e professores podem ser colocados nas extremidades de um continuum em que:

- Os alunos estão prontos a aprender a partir do detalhamento do conceito inicial, caracterizando-os como iniciantes no tema de estudo;
- Os professores já possuem uma rede de conceitos altamente interligada, caracterizando-os como especialistas.

\section{Aprendizagem Profunda e Superficial}

Uma das formas de explicar o processo de ensino-aprendizagem é a utilização de um modelo baseado nas mudanças de estrutura de conhecimento em dois ciclos possíveis, que remetem à aprendizagem superficial e profunda (Figura 4).

A primeira transformação do conhecimento acontece quando o professor, utilizando sua rede de conhecimento, prepara sua aula a partir da seleção dos conceitos a serem abordados (Figura 4, processo 1). O encadeamento conceitual obtido reflete uma estratégia orientada à consecução de um objetivo, qual seja, o de facilitar o aprendizado dos alunos. Iniciantes no tema de estudo, os alunos apresentam uma estrutura conceitual ti-

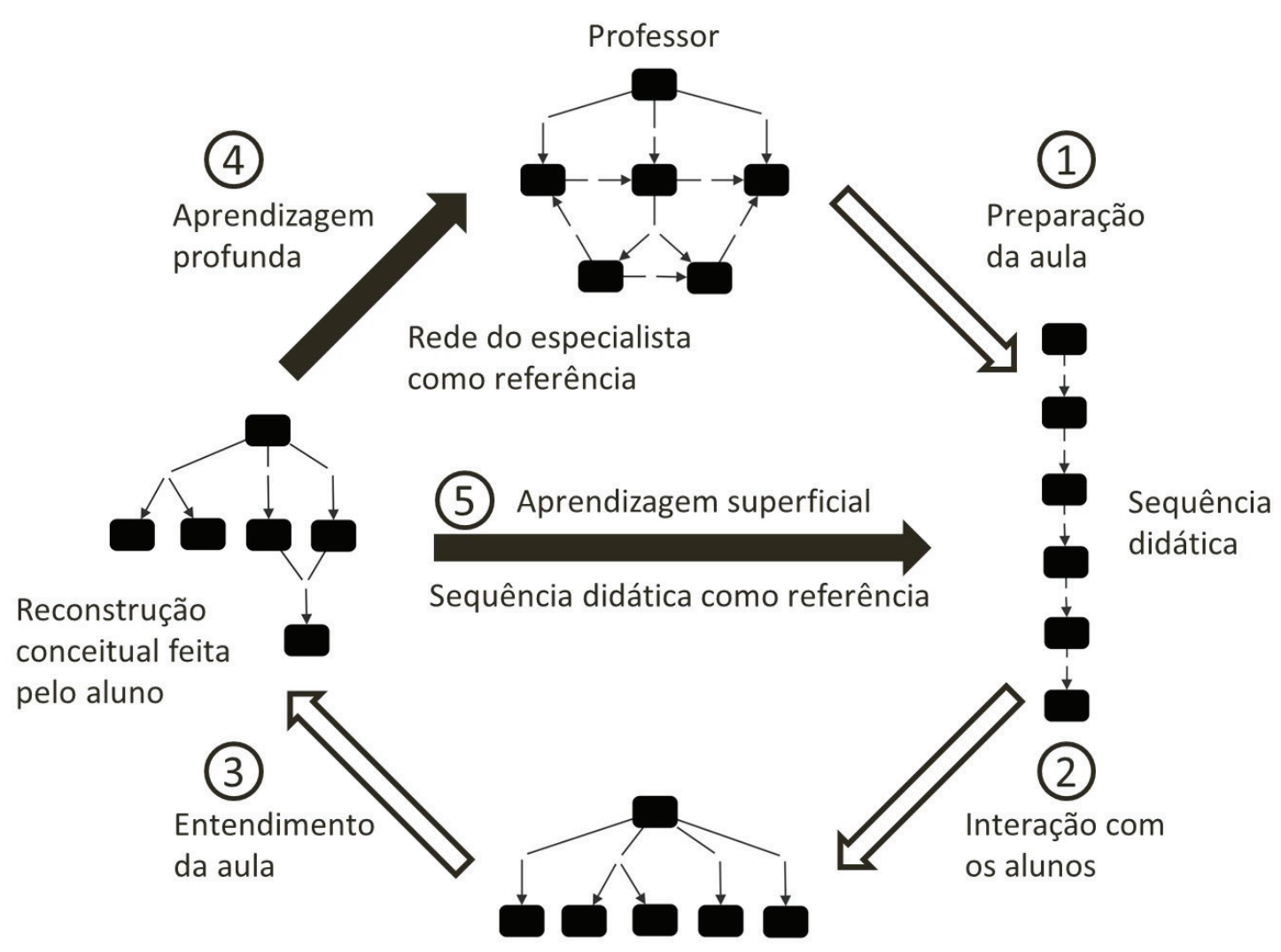

Aluno

Figura 4 - Ciclos de aprendizagem profunda e superficial descritos a partir das transformações da estrutura do conhecimento. As setas 1-3 indicam transformações no conhecimento. As setas 4-5 se relacionam com a avaliação da aprendizagem que tem como referência a rede do especialista e a sequência didática, respectivamente. Destaca-se a aprendizagem superficial como um atalho do ciclo de aprendizagem profunda. 
picamente radial. A realização das aulas permite a interação entre os conhecimentos dos alunos com a sequência didática elaborada pelo professor (Figura 4, processo 2). A partir do entendimento da aula, os alunos podem reconstruir suas estruturas conceituais (Figura 4, processo 3) para que, progressivamente, comecem a emergir especialistas em ascensão. Dois tipos de aprendizagem podem ocorrer durante esse processo, de acordo com o feedback oferecido pelo professor. Se, durante o processo de avaliação da aprendizagem, o professor adotar como referência a sequência didática (estrutura linear), a aprendizagem superficial será favorecida (Figura 4, processo 5) porque os alunos não têm acesso à estrutura de conhecimento do especialista: a interação professor-aluno se mantém a partir da sequência didática, que é uma versão parcial e simplificada do conhecimento especializado. Se, por outro lado, o professor utilizar como referência a sua rede de conhecimentos, a aprendizagem profunda será favorecida. Nesse caso, a regulação do processo de ensino-aprendizagem extrapola a organização conceitual das aulas e explora o entendimento do especialista (Figura 4, processo 4). A interação professor-aluno se mantém a partir da complexidade do conhecimento do especialista, criando oportunidades para que os iniciantes alcancem tal patamar mais avançado durante o decorrer da disciplina.

Os mapas conceituais tornam visíveis essas estruturas de conhecimento, bem como a sua transformação ao longo do tempo. Com isso, o professor é capaz de interagir com seus alunos, considerando o atual nível de entendimento que eles têm sobre os temas de estudo. Essa regulação da aprendizagem, por meio de feedbacks precisos e constantes, mostra-se importante para sustentar a opção dos alunos pela aprendizagem profunda.

Ambos os ciclos de aprendizagem ocorrem nas atividades acadêmicas do ensino superior. A aprendizagem superficial é predominante no ensino de graduação e, muitas vezes, de pós-graduação. Seja por fatores pessoais (visão fragmentada do conteúdo, a iniciativa de ministrar a disciplina pela primeira vez ou fora da área de especialidade) ou institucionais (regime de avaliação, reconhecimento profissional), o professor muitas vezes opera na "zona de conforto", organizando o processo de avaliação da aprendizagem de acordo com partes específicas da sequência didática. Já a aprendizagem profunda é predominante nas atividades de pesquisa, sejam elas de iniciação científica ou de pós-graduação. Nesses casos, o professor, atuando como mediador do processo de aprendizagem, busca do seu orientando as tomadas de decisões típicas do especialista. Ainda que professores e alunos sejam os mesmos, a opção por um determinado tipo de aprendizagem dá-se pela natureza do processo que será desenvolvido: a disseminação do conhecimento tende a favorecer a aprendizagem superficial; a produção de conhecimento estimula a aprendizagem profunda.

A possibilidade de visualizar a construção do conhecimento, potencializar a aprendizagem profunda e planejar feedbacks precisos e frequentes são os argumentos que justificam o uso dos mapas conceituais no ensino superior.

\section{Aplicações dos Mapas Conceituais no Ensino Superior}

Há várias formas de explorar os mapas conceituais no ensino superior. Estas podem ser organizadas em dois grupos distintos, de acordo com o autor do mapa conceitual (alunos e professores podem atuar como mapeadores). Em qualquer caso, é fundamental que o mapeador compreenda os princípios dessa técnica de representação do conhecimento. Uma etapa de treinamento deve ser prevista para apresentar os quatro parâmetros de referência para se elaborar bons mapas conceituais (AGUIAR \& CORREIA, 2013).

Ambas as aplicações podem cumprir diferentes objetivos educacionais, como por exemplo, para estudo, revisão, avaliação ou colaboração. A Tabela 2 apresenta as aplicações mais recorrentes na literatura para ilustrar várias possíveis formas de se utilizar os mapas conceituais em sala de aula.

Nas situações em que o aluno deve elaborar o mapa conceitual, convém ao professor prestar especial atenção na demanda de realização da 


\begin{tabular}{|c|c|}
\hline Objetivos educacionais & O aluno como mapeador \\
\hline $\begin{array}{l}\text { Organização do } \\
\text { conhecimento e } \\
\text { estudo }\end{array}$ & $\begin{array}{l}\text { 1. Listar conceitos-chave de um conteúdo } \\
\text { 2. Organizar informações relevantes } \\
\text { 3. Estabelecer conceitos mais gerais e mais } \\
\text { específicos a respeito de um conteúdo } \\
\text { 3. Estabelecer relações conceituais } \\
\text { 4. Descrever eventos ou objetos } \\
\text { 5. Descrever relações de causa e efeito } \\
\text { 6. Responder a uma pergunta focal ar- } \\
\text { ticulando proposições } \\
\text { 7. Sintetizar um conteúdo extenso ou } \\
\text { pouco articulado } \\
\text { 8. Hierarquizar conteúdos em um todo } \\
\text { coerente } \\
\text { 9. Sistematizar um projeto de pesquisa }\end{array}$ \\
\hline Revisão & $\begin{array}{l}\text { 1. Recuperar informações recém-apren- } \\
\text { didas } \\
\text { 2. Revisar conceitos, modelos, teorias } \\
\text { 3. Incluir novos conceitos à um mapa } \\
\text { conceitual já elaborado anteriormente - } \\
\text { expansão da rede de conceitos } \\
\text { 4. Utilizar como ponto de apoio para } \\
\text { fornecer feedbacks }\end{array}$ \\
\hline
\end{tabular}

1. Visualizar a escolha e a pertinência dos conceitos frente a um conteúdo

2. Visualizar o grau de articulação dos conceitos em proposições claras

3. Avaliar a escolha dos verbos para formar proposições

Avaliação

Colaboração
4. Potencializar a metacognição - pensar sobre o seu próprio conhecimento

5. Identificar lacunas conceituais ou conceitos mal compreendidos

6. (Re)pensar o seu processo de aprendizagem

7. Autoavaliar o conhecimento aprendido

\section{Negociar conceitos e significados}

2. Treinar argumentação e comunicação

3. Potencializar trabalho em equipe focado, por exemplo, a construção de um mapa conceitual em grupo

4. Contrastar e comparar diferentes pontos de vista, modelos, teorias, panoramas
Aplicações

O professor como mapeador

1. Realizar a abertura de uma disciplina mostrando sua macroestrutura, a dinâmica e a organização

2. Realizar a abertura de um novo conteúdo ou tema

3. Articular diferenças e semelhanças entre teorias

4. Articular conteúdos entre disciplinas

5. Descrever um processo complexo

6. Organizar informações de modo hierárquico

7. Evidenciar conteúdos que vieram de diferentes fontes de informação

8. Expandir discussões a partir de conceitos controversos

9. Planejamento curricular

1. Revisar um conteúdo a partir dos conceitos mais importantes

2. Sintetizar conteúdos extensos

3. Articular diferentes momentos de uma disciplina

4. Apresentar, discutir, revisar conceitos críticos

5. Sanar dúvidas e fornecer feedbacks pontuais

1. Levantar conhecimentos prévios

2. Solicitar que os alunos reconheçam erros conceituais intencionalmente planejados pelo professor

3. Solicitar uma síntese de conceitos frente à adequação de um pergunta focal

4. Avaliar a organização hierárquica de conceitos

5. Selecionar termos de ligação pertinentes dentre uma lista

6. Finalizar um mapa conceitual iniciado em sala 7. Solicitar a inclusão de novos conceitos à rede após uma aula

1. Realizar uma atividade de avaliação por pares

2. Explicar e argumentar em cima de um ponto de vista

3. Reconstruir o mapa de modo colaborativo

4. Reconhecer e reunir conceitos em comum em diferentes pontos de vista

5. Promover discussão em grupo

Tabela 2 - Exemplos de aplicações de mapas conceituais em que o aluno e/ou o professor os elaboram para cumprir objetivos educacionais relacionados à organização de conhecimento, estudo, revisão, avaliação e colaboração. 
atividade, ou seja, na forma por meio da qual o mapa conceitual será solicitado. A demanda contém as condições em que ele deve ser elaborado para que se atinja um objetivo educacional específico. Nesse caso, pode-se trabalhar com uma série de fatores como limitação do número de conceitos, presença de conceitos obrigatórios, perguntas focais estabelecidas pelo professor e até aspectos de ordem mais prática como o tempo de execução da tarefa e a possibilidade de consulta dos materiais instrucionais. Existem várias formas de usar os mapas conceituais e é possível encontrar uma que melhor atende cada objetivo de ensino. Cabe ao professor, como especialista do assunto, definir tais objetivos e determinar as melhores condições de utilização dos mapas conceituais para que seus alunos se tornem futuros especialistas.

\section{Conclusão}

Na literatura especializada já existem diversos trabalhos que demonstram o uso de mapas conceituais aos mais diversos conteúdos e níveis de ensino ${ }^{2}$. Entretanto, o uso inadequado dessa técnica de representação do conhecimento em sala de aula pode apresentar alguns entraves, como alunos que "empacam" diante de uma folha em branco, ou que elaboram mapas conceituais simplórios para o nível de conhecimento que possuem.

Diante desses problemas, recomendamos que os interessados no uso dos mapas conceituais em sala de aula considerem os seguintes aspectos:

1. É necessário o domínio da técnica de mapeamento conceitual pelos professores, a partir da compreensão dos quatro componentes chaves do mapeamento. Sugerimos que antes de realizar essa atividade em sala de aula, o professor elabore um mapa conceitual sobre um conteúdo que conheça para compreender como essa é uma atividade que requer esforço dos alunos e, assim, tenha dimensão de eventuais dificuldades que possam surgir no processo. Com essa atividade, torna-se claro como é necessário o treinamento prévio dos alunos na técnica.

2. É necessário planejamento de ensino quando se tem como objetivo utilizar mapas conceituais. Estes não podem surgir como um aspecto com- plementar ou ilustrativo no processo. Na verdade, espera-se que sua execução permita o desenvolvimento cognitivo do aluno. Quando se constrói o planejamento dessa maneira, torna-se necessário o uso recorrente dos mapas conceituais para que se altere a dinâmica de ensino-aprendizagem e se amplifiquem as possibilidades para que ocorra uma maior ressonância pedagógica entre aluno e professor.

As novas demandas formativas da sociedade do conhecimento exigem a busca por respostas inovadoras para transformar o ensino de graduação. Essa busca precisa valorizar a interação entre alunos e professor, visando à construção de estruturas de conhecimento em rede por meio da aprendizagem profunda. Os mapas conceituais tornam visíveis tais estruturas de conhecimento e, por isso, eles se mostram úteis no planejamento, na execução e na avaliação do processo de ensino-aprendizagem. Apesar disso, é evidente a insuficiência dos mapas conceituais para resolver todos os problemas existentes nas salas de aula. Nosso grupo de pesquisa trabalha para compreender como essa técnica de representação do conhecimento pode se combinar com outras estratégias de ensino, de forma a gerar modelos práticos que podem ser úteis a professores e alunos. É possível utilizar os mapas conceituais para aprender profundamente, aprender a aprender e a aprender por toda a vida.

\section{Agradecimentos}

Nosso grupo de pesquisa agradece ao $\mathrm{CNPq}$ (486194/2011-6; 440686/2014-8), à CAPES (PAEP 2598/2014) e à FAPESP (2012/22693-5; 2014/093370) pelo apoio financeiro. Joana Aguiar agradece à CAPES pela bolsa de doutorado. Anderson Viana agradece à FAPESP (2014/03367-5) pela bolsa de mestrado.

\section{Notas}

1. Gratuito, o programa CmapTools é dedicado à elaboração de mapas conceituais. Visite o site <http:// cmap.ihmc.us/ $>$ para maiores informações a respeito.

2. Os proceedings das conferências internacionais sobre mapas conceituais contêm um rico repertório de pesquisas e experiências educacionais. O conteúdo está disponível gratuitamente em <http://cmc.ihmc.us/ cmc/CMCProceedings.html $>$. 


\section{Referências Bibliográficas}

AGUIAR, Joana Guilares de \& CORREIA, P. R. M. "Como Fazer Bons Mapas Conceituais? Estabelecendo Parâmetros de Referência e Propondo Atividades de Treinamento". Revista Brasileira de Pesquisa em Educação Científica, vol. 13, n. 2, 2013, pp. 141-157.

CAÑAS, Alberto J.; NOVAK, J. D.; REISKA, P. "How Good is My Concept Map? Am I a Good Cmapper?" Knowledge Management \& E-Learning, vol. 7, n. 1, 2015, pp. 6-19.

CORREIA, Paulo R. M. "The Use of Concept Maps for Knowledge Management: from Classrooms to Research Labs". Analytical and Bioanalytical Chemistry, vol. 402, n. 6, 2012, pp. 1979-1986.

FRIEDMAN, Thomas L. O Mundo é Plano: uma Breve História do Século XXI. Rio de Janeiro: Objetiva, 2007.

HAY, David B. "Using Concept Maps to Measure Deep, Surface and Non-learning Outcomes". Studies in Higher Education, vol. 32, n. 1, 2007, pp. 39-57.

HAY, David B.; KINCHIN, I. M.; LYGO-BAKER, S. "Making Learning Visible: the Role of Concept Mapping in Higher Education". Studies in Higher Education, vol. 33, n. 3, 2008, pp. 295-311.

IFENTHALER, Dirk and HANEWALD, R. Digital Knowledge Maps in Education: Technology-Enhanced Support for Teachers and Learners. Nova York: Springer, 2014.

KINCHIN, Ian M. and HAY, D. B. "How a Qualitative Approach to Concept Map Analysis can be Used to Aid Learning by Illustrating Patterns of Conceptual Development". Educational Research, vol. 42, n. 1, 2000, pp. 43-57.

KINCHIN, Ian M.; LYGO-BAKER, S.; HAY, D. B. "Universities as Centres of Non-learning". Studies in Higher Education, vol. 33, n. 1, 2008, pp. 89-103.

MOON, Brian M.; HOFFMAN, R. R.; NOVAK, J. D.; CAÑAS, A. J. Applied Concept Mapping: Capturing, Analyzing, and Organizing Knowledge. Boca Raton, Flórida: CRC Press, 2011.

NOVAK, Joseph D. Learning, Creating and Using Knowledge: Concept Maps as Facilitative Tools in Schools and Corporations. 2 ed. Nova York: Routledge, 2010.

NOVAK, Joseph D. \& CAÑAS, A. J. "Theoretical Origins of Concept Maps, How to Construct them, and Uses in Education". Reflecting Education, vol. 3, n. 1, 2007, pp. 29-42.

TORRES, Patricia Lupion \& MARRIOTT, R. C. V. Handbook of Research on Collaborative Learning Using Concept Mapping. Hershey, Pensilvânia: IGI Global, 2010.

UNESCO. Towards Knowledge Societies: UNESCO World Report. Paris: UNESCO Publishing. 2005.

Publicado em 05/07/2016. 
